\title{
A Case for "Radiolysis" in Radiotherapy of Keloids
}

\author{
K. Malaker1', H. Weatherburn'2, H. De Souza' ${ }^{2}$ \\ ${ }^{1}$ Department of Clinical Medicine, Ross University School of Medicine, Portsmouth, Dominica \\ ${ }^{2}$ Cancer Centre of London, London, UK \\ Email: Kamal malaker@hotmail.com, Henry.weatherburn@cancercentrelondon.co.uk, \\ Harold1966@rediffmail.com
}

Received 22 July 2014; revised 21 August 2014; accepted 20 September 2014

Copyright (C) 2014 by authors and Scientific Research Publishing Inc.

This work is licensed under the Creative Commons Attribution International License (CC BY).

http://creativecommons.org/licenses/by/4.0/

(c) (i) Open Access

\section{Abstract}

Successful treatment of keloids has eluded the medical community since their first description. Multitudes of therapeutic options are available, but none achieves satisfactory resolution of keloids. One major stumbling block is lack of understanding about their genesis. Assuming keloids are tumors, attempts have been made to treat this condition with standard radiotherapy, with dismal results. Keloidal masses are not an active biological entity. They are aggregations of cellular, hypovascular, hypoxic bundles of collagen, which are produced by atypical fibroblasts in the wounds and eventually cease production due to a hostile biological environment. Having no demonstrable inherent process of disposal of these collagen bundles, this excessive collagen tends to linger to form the bulk of keloids. The lesions eventually become symptomatic and aesthetically unacceptable, and therapeutic intervention is sought. Of all available treatments, such as post-resection radiotherapy, primary radiotherapy in selected cases and primary brachytherapy stand out above any other form of treatment. Be it brachytherapy or external beam treatment, one fundamental aspect of radiation action is the process of "radiolysis", explaining why "radiobiological" approaches have been ineffective.

\section{Keywords}

Radiotheraphy, Radiolysis, Keloid Treatment

\section{Introduction}

Radiotherapy as a part of management of keloidal lesions is well established. Common use is postoperative irradiation by external beam radiation in the management of hypertrophic scars and keloids [1]-[3] and interstitial 
irradiation [4]-[6]. Radiation has rarely been used as a primary modality by external beam [6]-[8]. Primary radiotherapy without surgical excision has mostly been unsatisfactory, from keloid resolution, symptomatic and cosmetic points of view [1] [4] [5] [7] [9] [10]-[13]. There has been a satisfactory response to primary radiation for surgically unrescectable, post-operative and post-radiotherapy recurrences, using high-dose hypo-fractionated radiotherapy [7] [10] in keloid regression and flattening, and resolution of symptoms and cosmetic benefits have been achieved. Efforts to treat unresectable keloids with primary brachytherapy have been mostly unsatisfactory with unacceptable outcomes [11]-[13]. Without surgical removal of keloids the results so far have been dismal. Unfortunately, with surgical resection only, keloids have up to 90\% recurrence [14] [15], frequently worse than their pre-excision state. Very large and multiple keloids are not amicable to surgical resection. For the same reason large keloids are unsuitable for repeated intra-lesional injection of steroids, instillation of proteolytic enzymes [16] or even oral Tamoxifen [17].

Intra-lesional excision is a new approach to debulk keloid mass or achieve keloid core excision results in flattening of the lesion, relief of symptoms and cosmetic benefit, without the high degree of recurrence seen in classical excision [18]-[20]. Druitt [21] first laid the foundation of modern surgical excision of keloids. Several modifications have been adopted to reduce post-surgical recurrence since then, for example, keloid auto-grafts [22]-[24]. In reality, the biological effect of leaving behind a rim of keloid is more likely to cause relatively active, well oxygenated fibroblasts to move into the cycling and dividing phase, capable of further keloid proliferation [25]. None of the altered surgical excisions led to prevention of recurrences. Yet, surgical excision followed by post-operative radiotherapy remains the gold standard in treatment of keloids [26] [27].

Keloids are a non-life threatening condition, yet patients seek assistance from doctors for various reasons, for example, mild to severe itching, pain, irritation, uncomfortable masses or lumps, unsightly appearance, functional impairment, cosmesis, social stigma, and depression [28] [29]. Of all these symptoms insatiable itching, cosmesis, and restriction of physical activities due to massive keloids are the most likely reasons for seeking medical attention. Irrespective of the modality of treatment, unless the keloid is significantly flattened the therapeutic effect should be considered inadequate, in spite of successful symptomatic relief [30]. In his extensive and exhaustive review of treatment of keloids, in seven (7) different categories-i.e., surgery alone; lasers alone; radiation alone; surgery plus radiation; intra-lesional steroids alone; surgery plus steroids; varieties of other agents and modalities with or without surgery-Lawrence [30] concluded that there is no consensus as to management of keloids. However, the majority of reports indicated results of the regimen showed "significant objective response" [31]. The tools for measurements of objective response remain unclear. Some investigators based their findings on symptomatic improvement, reduction of keloid thickness and the lesion being more supple and softer on palpation. Specifics of the objectivity are missing from most of the reports. Very few studies [7] reported complete flattening of the lesion, which should be our main objective aside from symptomatic relief in the management of keloids.

Once keloidal collagens are formed, they stay forever, only atrophying in synchrony with advancing age, along with the skin and its integuments [32]. The dynamics of the metabolism of established keloidal collagen is unclear [33] at this point in time, including that of non-keloidal collagens in wounds, scars or normal tissue, for that matter.

\section{Introspection of Radiotherapy of Keloids: Shortcomings of Standard Fractionated Radiotherapy and Applicability of Alpha-Beta Ratio}

\subsection{Radiotherapy}

Radiotherapy for cancer treatment is based on the principles of 4R: repair, re-oxygenation, redistribution and repopulation. Fundamentally it exploits the differential recovery between the non-cancerous and cancerous cells. In classical fractionated radiotherapy the objective is to kill the maximum number of cancerous cells and allow the maximum number of irradiated normal cells to recover from radiation damage. Whether it is the fraction size, inter-fraction interval, quality of radiation [34] [35], brachytherapy [36], radio sensitizers or radio protectors [37] [38], all exploit the 4R principles [39] to enhance the therapeutic advantage, which is heavily dependent on cycling cells and state of tissue oxygenation. These are essential biological factors, aside from reassortment and repopulation. The "primary targets" for radiation are cancer cells, which is the main constituent, more than $50 \%$ $80 \%$, of a tumor, in addition to blood and lymphatic vessels, matrix "cellular and non-cellular" components, all of which constitute the tumor volume. In cancer radiation, volume reduction is achieved by clonogenic death of 
dividing cells or apoptotic death of the rest. The delayed effect of fractionated radiotherapy is achieved on the same principle, also affecting the micro-vascularity, achieving atrophy and further volume reduction [40] [41]. The process of fractionated radiotherapy does not address the role played by radiation on the connective tissue in tumor volume reduction.

The concepts of Relative Biological Effect (RBE) and Alpha/Beta ratio are influenced by radiation quality, number of doses per fraction, dose rate and biologic system or end point [42]. All these factors evaluate the effect of radiation on the cellular component of the tumor and not on the a-cellular, scantily-cellular or biologically relatively inert component, that is, the connective tissues. Yet connective tissues which are poorly cellular do respond to radiation by regression, not due to clonogenic cell death in the acute phase, but most likely due to the direct effect of radiation at the molecular level of the constituents of connective tissue. Delayed atrophy of connective tissue, known to be due to radiation-induced micro-angiopathy [42], is a minor component of regressing bulk of the connective tissue. It appears that, besides clogenic cell death and micro-vasculopathic atrophy, some other radiation-induced mechanism is at play for the final tumor regression.

"Radiolysis", a radiation-induced "proteolysis", appears to be the most likely process involved in regression of irradiated tumors. This involves initiation of the radio-biologic process, as well as radio-chemical lysis of acellular or hypo-cellular components of the tissue or tumor.

\subsection{Radio-Surgery}

The radio-surgical approach to radiotherapy works entirely on a different principle, which is independent of cell cycle or the 4R principles of radiobiology. Few clinical conditions are treated by radio-surgery. In radio-surgery a single high dose or a few fractionated high doses of radiation is applied, aiming particularly at cases of AVM (atrio-venous malformation). Vascular tissue and other cellular components react by the development of myofibroblasts in the irradiated volume, causing contracture and reduction of the aneurismal space. Gradual depletion of irradiated cells is replaced by scar tissue. Thus obliteration of the offending aneurysm is achieved [43] [44] due to radio-necrosis of the target tissue through radiolysis, a physical phenomenon, independent of the basic principles of modern clinical radiobiology, the 4 Rs. Yet with precision treatment planning, surrounding normal non-targeted tissues are spared [45]. Some modifications of the delivery of radiation for radio-surgery have been adopted using the fractionated technique, aiming to achieve better protection of normal, non-targeted tissue, yet still using a high dose per fraction, to induce radio necrosis through radiolysis.

\subsection{Radiolysis of Keloid Collagen}

Radiolysis of keloid collagen is fundamentally a proteolytic process induced by ionizing radiation.

The fact that ionizing radiation can induce proteolysis at a lower dose has been clearly demonstrated by Weik et al. [46], using synchrotron radiation causing highly specific damage to the protein molecules. By using Torpedo California Acetylcholine Esterase (TCACE)—synchrotron radiation—specific changes, i.e., 1) disulphide bridge break; 2) loss of definition of acidic residue of carboxyl group, and 3) putative "Weak-Link" of other biological macromolecules have been ascertained. This has a wide application in understanding the role of ionizing radiation in the induction of proteolysis. Radiolysis of water molecules producing toxic radicals secondarily causing DNA damage as result of ionizing radiation to cells and tissues is well established. Ionizing radiation can cause irreversible alteration of protein conformation at the molecular level, i.e., fragmentation in the presence of oxygen and aggregation under hypoxic [47] conditions. For the same dose the extent of denaturation of protein induced by y-rays is much lower in a dry state than in an aqueous state. The differential effect is due to a direct effect in dry substrates and direct and indirect effects in wet substrates. The protein alteration due to Y radiation in the aqueous phase is due to the formation of free radicals by water radiolysis, which is a "radiochemical process" rather than a radio-biological one [48]. This is achieved between 1 - $10 \mathrm{Krad}$ (1000 cGy 10,000 cGy [48]. Radiolysis of proteins can be achieved both under oxygenated and hypoxic conditions, but is significantly more pronounced in a well-oxygenated state. Mainly aggregation reactions are seen in well-oxygenated states, caused by covalent-non covalent interaction in protein molecules [49] [50].

Keloids are formed by highly dense, tightly packed, poorly vascularized, poorly oxygenated collagenous material. The basic building blocks of collagen molecules are glycin, proline and hydroxyproline. These components are expected to undergo radiolysis following exposure to ionizing rays or radiolysis. In keloidal collagen sparsely distributed interstitial fibroblasts, without any mitotic activities, are mostly resting [50]-[52]. These in- 
terstitial fibroblasts, however, continue to produce huge amounts of biologically inert collagen, which are deposited locally until the fibroblast stops producing collagen and stops replicating, resulting in self limitation of keloid growth [53] [54].

With a standard dose of fractionated radiotherapy, results of keloid regression have been dismal [55] [56], essentially because the bulk of the keloid is made up of biologically inert collagen, a hypoxic environment, and hypoxic fibroblasts [51]. However, post-operative radiotherapy for keloids is largely successful because the post-operative target is the well oxygenated, neo-vascularized, replicating fibroblasts, which are relatively more sensitive to fractionated radiotherapy than quiescent hypoxic resting fibroblasts of keloidal tissues. Larger fraction-sized radiation produces better results than standard $200 \mathrm{cGy}$ daily fractionation. The dynamics of turnover of keloidal collagen from its natural history [50] are apparently much slower than non-keloidal collagen in the body, if it exists.

One important objective for treatment of keloids is cosmesis. This quickly achieved by removal of the keloidal mass surgically. For smaller keloids and hypertrophic scars local infiltration of pharmacological agents with or without pressure may achieve complete flattening. These lesions are not clinical problems. Lesions with larger keloidal-collagen burdens are poorly affected by local infiltration of pharmacological agents with or without pressure and remain unmoved by keloidal content; thus the objective for achieving any form of cosmesis remains unfulfilled.

However Surgery by physically removing the keloidal collagenous mass achieves, either fully or partially, the objective of an improved cosmetic effect.

Radio-surgery aims at coagulating tissues by necrosis (later removed by macrophage system from the site of radio-surgery), induced by very large fractional doses of radiation. This induction of "controlled therapeutic radio-necrosis" is the mode of action in radio-surgery. This is independent of tissue oxygenation, fibroblasts and other cells' state of vegetation, vascularity, etc. The success of radio-surgery using this principle is well documented.

Hence, success and an improved cosmetic effect for keloids treated by large fraction size radiotherapy can be rationalized and explained on a similar basis as radio-surgical principle.

As opposed to radio-surgery, which aims for total necrosis or fibrosis, the objective in the case of keloid treatment with large fraction radiotherapy is not to induce total necrosis but to eliminate or reduce keloidal collagen maximally to achieve the best "cosmesis". Differential retention of non-keloidal collagenous tissue is another objective (Table 1).

Table 1. Comparism of parameters between radiotherapy, radiosurgery and radiolysis.

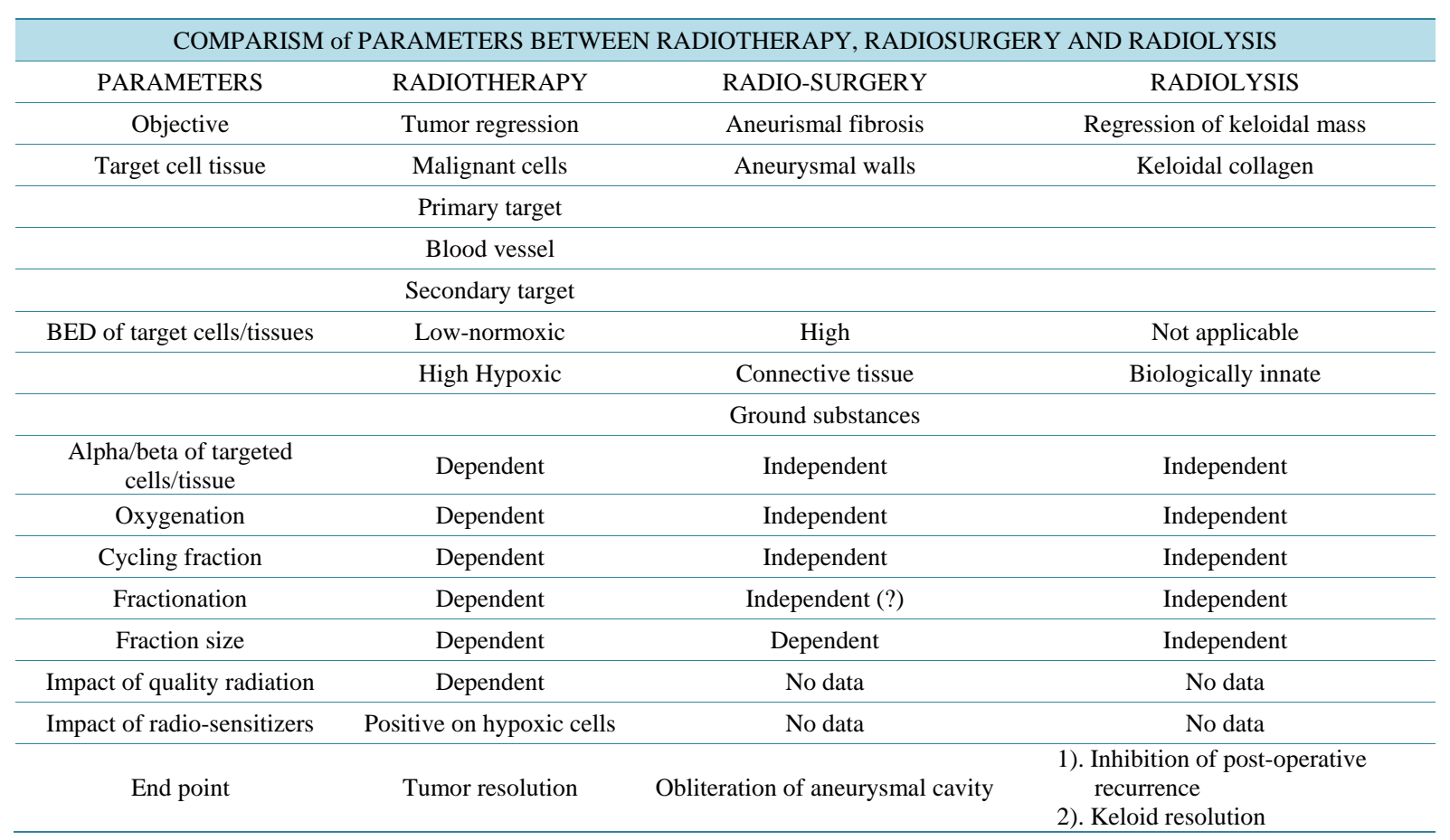




\section{Lesions Learned from Post-Operative Radiotherapy and Keloid Core Resection}

The above review and an extensive literature search confirms that if the keloid is surgically resectable, complete keloid resolution is best achieved by giving post-operative radiation [1]-[3]. To reduce post-surgical skin tension instead of performing extra keloidal resection, intra-keloidalcore resection or Cleido-cutaneous margin sparing surgery (CCMSS), followed by a course of radiotherapy, does provide excellent resolution and cosmetic benefits. Due to minimal or no tension of the skin flaps, this type of surgery has been shown to be more effective [57][59].

In this surgical procedure the main benefit is the physical removal of the keloidal mass, which gives the best result for the treatment of keloids.

When the keloid removal or core resection is not practically feasible, then the alternative will be to search for a possible way to "lyse”, or liquefy, the keloid mass and then leave it to the body's own disposal mechanisms, i.e., lymphatics, venous drainage and scavenging system to facilitate drainage or removal of the lysed or liquefied collagen and degradation products. This will take us close to achieving the goal of total or maximal keloid resolution.

\section{Radiotherapy for Keloid Treatment}

Several reviewed papers indicated that the best way to deliver radiation to keloids is to give fewer fractions and higher doses per fraction [60]. Malaker et al. have demonstrated, by treating unresectable and recurrent keloids with 750 cGy weekly, to a total dose of 3750 cGy in 5 fractions (Table 2). Similarly Guix, using high-dose rate brachytherapy, achieved very high cure rate (Table 2). The biological effect of high-dose rate brachytherapy is not fully cell cycle- or clonogenic cell death-dependent. A major component of keloid regression is due to radiolysis, as one can envisage from the rate and degree of reduction of keloidal collagen [61].

\section{Discussion}

The fundamental action of radiation is to induce ionization; hence it is called ionizing radiation, which is a radio-chemical phenomenon. But simple ionization of the ionizable component of an irradiated tissue does not deliver our objective of cellular damage for curing cancer, for which it is used. Processes beyond ionization, involving cell death and cure of cancer, depend on other biological factors, for example, tissue oxygen tension,

Table 2. Radiotherapy for keloid treatment: A comparism between external beam and brachytherapy.

\begin{tabular}{|c|c|c|}
\hline \multirow[t]{2}{*}{ PARAMETERS } & \multicolumn{2}{|c|}{ TECHNIQUES } \\
\hline & External Beam (Malaker et al.) & Brachytherapy (Duex et al.) \\
\hline No. of Keloids & 86 & 22 \\
\hline \multirow[t]{2}{*}{ Radiotherapy Dose } & 3750 cGy in once weekly & 1800 cGy in $6 \mathrm{~F} \times \mathrm{TID}$ \\
\hline & 750 cGy/fraction $\times 5$ weeks & 300 cGy/F 9 am, 3 pm, 9 pm \\
\hline Duration of treatment & 35 days & 2 days \\
\hline Follow up period & 25 yrs & 7 yrs \\
\hline \multirow[t]{3}{*}{ Response } & 97\% complete regression & 85.4\% complete response \\
\hline & $3 \%$ poor responder & $13.6 \%$ recurrence \\
\hline & $100 \%$ complete asymptomatic & 97\% complete asymptomatic \\
\hline Long-term side effect & 15.5\% telangiectasia & $<1 \%$ telangiectatic \\
\hline Carcinogenesis & Nil reported & Nil reported \\
\hline \multirow[t]{2}{*}{ Observations } & $\begin{array}{c}\text { Most effective independent of radiobiological } \\
\text { restriction }\end{array}$ & $\begin{array}{c}\text { Highly effective short treatment period } \\
\text { compliant with accepted } \\
\text { brachytherapy-radiobiology, but independent } \\
\text { of fraction radiobiology require brachytherapy } \\
\text { facility }\end{array}$ \\
\hline & Easily adopted in any basic radiotherapy center & Hence restricted due to logistics \\
\hline
\end{tabular}


amount of cycling cells, inherent cellular radio-sensitivity, and quality of radiation, all of which are important contributors for the ultimate eradication of cancerous cells in order to achieve a cure. Body tissues comprise a small proportion of living cells compared to the much higher proportion of a-cellular products, which are made of basically either simple or complex molecules, i.e., the extra-cellular matrix, the ground substance, most of the connective tissue component and the water content of our body. Water, being an inanimate content of our tissue, does have a profound effect on cellular biology when subjected to ionizing radiation. The indirect effect of ionized charged radicals of water is to cause significant damage to various components of living cells including DNA, leading to small reversible or serious irreversible damage to the cell and ultimately manifesting the radiobiological effects of radiation. The initial process is radio-chemical and not radiobiological. Indeed to alter the radio-sensitivity of cells, attempts have been made to take advantage of this initial radiation-induced ionization or radiolysis process to facilitate or decelerate the biological effects using various chemicals or physical agents like "Hyperthermia", etc.

While treating cancer with radiation our "target" is primarily the cancer cells and the supporting cells secondarily. Radiation can either directly hit the cellular genomic contents or indirectly affect them through the production of highly charged free radicals, i.e., $\mathrm{O}^{2}$ radicals or $\mathrm{HO}$ radicals, which damage the genomic component of cells, or cellular integuments, leading to cell death. Damaging cancer cells is the targeted action.

In case of keloids, the bulk of the lesion is formed by collagen, which is a complex protein and not made of the cells. The bulk of the keloid must be removed to achieve our objective of keloid resolution (independent of its sparsely distributed hypoxic cells, which are relatively radio-resistant). Without dispersal of the keloidal mass, one can hardly achieve the objective of cosmoses of any degree. Surgical removal does it. Without any planned post-operative adjuvant therapy, the recurrence is guaranteed up to $90 \%$. By using classical radiobiological techniques and principles of fractionated radiotherapy, treatment of keloid is essentially a failure, since very few "hypoxic", "non cycling" and inherently radio-resistant fibroblasts are present in the interstices of a keloid that do not respond to classical fractionated radiotherapy regimen.

Keloids being protein, however complex, they are amenable to external beam radiation for "proteolytic" changes, a chemical event, eventual "radiolysis" leading to keloid resolution and a cure. Hence, treating keloids with radiation is a phenomenon of a "radio-chemical process" and not a "radiobiological" one (Figure 1).

\section{Conclusion}

High fraction size and low fraction number is likely to be the dictum for keloid radiation treatment, whether it is used as primary therapy or as an adjuvant, which works through "radiolysis", a radio-chemical process, and not on radiobiological principles. We have manipulated the radiobiological aspect of radiotherapy in various ways, i.e., altering fractionation, concurrent boost, hyper-fractionation, using radio-sensitizers, radio-protectors, chemo-radiation, etc.

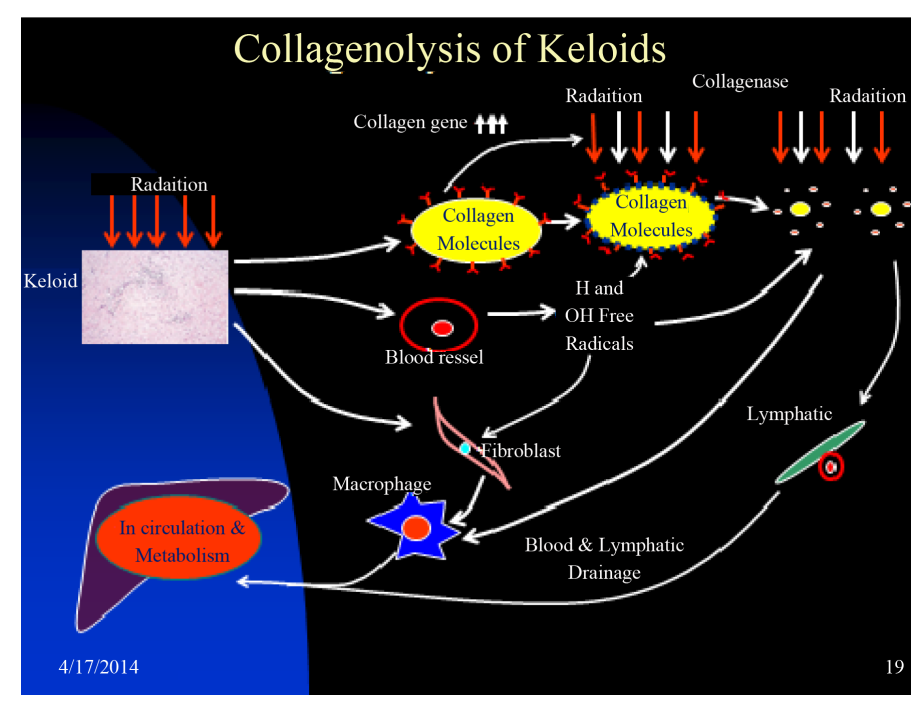

Figure 1. Schematic diagram of radiolysis of keloidal collagen. 
Although the radiolytic process is fundamental in the initiation of the radiobiological process, few or no innovative attempts have been made to alter or manipulate this fundamental action in radiotherapy to improve the therapeutic index. The success of treatment of keloids using the process of "radiolysis" is in our opinion an eyeopener. Other physical processes such as hyperthermia, ultrasound, and non-thermal radiofrequency all may have an impact on this initial process of "radiolysis" to enhance its biological or non-biological effect in curing tumors.

\section{Acknowledgements}

Ms. Joan Joseph provided secretarial assistance and Mr. Irus Toussaint provided all technical assistance.

\section{References}

[1] Van Den Brenk, H.A.S. and Minty, C.C.J. (1960) Radiation in the Management of Keloids and Hypertrophic Scars. British Journal of Surgery, 47, 595-605. http://dx.doi.org/10.1002/bjs.18004720603

[2] King, G.D. and Salzmann, F.A. (1970) Keloid Scars: Analysis of 89 Patients. Surgical Clinics of North America, 50, 595-598.

[3] Edsmyr, F., Larsson, L.G., Onyango, J., et al. (1974) Radiation Therapy in the Treatment of Keloids in East Africa. Acta Radiologica, 13, 102-106. http://dx.doi.org/10.3109/02841867409129869

[4] Malaker, A., Ellis, F. and Paine, C.H. (1976) Keloid Scars: A New Method of Treatment of Combining Surgery with Interstitial Radiotherapy. Clinical Radiology, 2, 179-183. http://dx.doi.org/10.1016/S0009-9260(76)80141-9

[5] Escarmant, P., Zimmerman, S., Amar, A., et al. (1993) The Treatment of 783 Keloid Scars by Iridium. 192 Interstitial Irradiation after Surgical Excision. International Journal of Radiation Oncology, Biology, Physics, 26, 245-251. http://dx.doi.org/10.1016/0360-3016(93)90204-9

[6] Guix, B., Henriquez, I., Andres, A., et al. (2001) Treatment of Keloids by High-Dose-Rate Brachytherapy: A Seven Year Study. International Journal of Radiation Oncology, Biology, Physics, 50, 167-172. http://dx.doi.org/10.1016/S0360-3016(00)01563-7

[7] Malaker, K., Vijayraghavan, K., Hodson, I. and Al Yafi, T. (2004) Retrospective Analysis of Treatment of Unresectable Keloids with Primary Radiation over 25 Years. Clinical Oncology, 16, 290-298. http://dx.doi.org/10.1016/j.clon.2004.03.005

[8] Deka, B.C., Deka, A.C., Avadhani, J.S., et al. (1987) Treatment of Keloids with Strontium 90 Beta Rays. Indian Journal of Cancer, 24, 15-21.

[9] Belisario, J.C. (1957) The Treatment of Keloids. Acta Dermato-Venereologica, 37, 165-181.

[10] Vera, A., Weatherburn, H. and Malaker, K. (2013) A case of Post Varicella Recurrent Presternal Butterfly Keloid. International Journal of Medical Physics, Clinical Engineering and Radiation Oncology, 2, 88-91. http://dx.doi.org/10.4236/ijmpcero.2013.23012

[11] Ramakrishnan, K.M., Thomas, K.P. and Sundaranajan, C.R. (1974) Study of 1000 Patients with Keloid in South India. Plastic \& Reconstructive Surgery, 53, 276-280. http://dx.doi.org/10.1097/00006534-197403000-00004

[12] Van den Brenk, H.A. and Minty, C.C. (1960) Radiation in the Management of Keloids and Hypertrophic Scars. British Journal of Surgery, 47, 595-605. http://dx.doi.org/10.1002/bjs.18004720603

[13] Inalsingh, C.H. (1974) An Experience in Treating Five Hundred and One Patients with Keloids. Johns Hopkins Medical Journal, 134, 284-290.

[14] Oluwasanmi, J.O. (1974) Keloids in the Africans. Clinics in Plastic Surgery, 1, 179-195.

[15] Cosman, B., Crikelair, G.F., Ju, M.C., Gaulin, J.C. and Lattes, R. (1961) The Surgical Treatment of Keloids. Plastic and Reconstructive Surgery, 27, 335-358.

[16] Chen, M.A., Davidson, T.M. and Terence, M. (2005) Scar Management: Prevention \& Treatment Strategies. Current Opinion in Otolaryngology \& Head \& Neck Surgery, 13, 242-247.

http://dx.doi.org/10.1097/01.moo.0000170525.74264.f8

[17] Gangnani, A., Warde, M., Furtadu, F. and Ferreira, L.M. (2010) Topical Tamoxifen Therapy in Hypertrophic Scars or Keloids in Burns. Archives of Dermatological Research, 302, 1-4. http://dx.doi.org/10.1007/s00403-009-0983-1

[18] Lee, Y, Minn, K.W., Baek, R.M. and Hong, J.J. (2001) A New Surgical Treatment of Keloids: Keloid Core Excision. Annals of Plastic Surgery, 46, 135-140. http://dx.doi.org/10.1097/00000637-200102000-00008

[19] Donkor, P. (2007) Head and Neck Keloids: Treatment by Core Excision and Delayed Intralesional Injection of Steroid. Journal of Oral and Maxillofacial Surgery, 65, 1292-1296. http://dx.doi.org/10.1016/j.joms.2006.10.049 
[20] Sunohara, M., Ozawa, T., Harada, T., Morimoto, K. and Ishii, M. (2012) A Technique for Auricular Keloid Core Excision Using a Skin Biopsy Punch. Aesthetic Plastic Surgery, 36, 628-630. http://dx.doi.org/10.1007/s00266-011-9858-x

[21] Druitt, R. and Joshua, B.F. (1844) The Principles and Practice of Modern Surgery. 3rd Edition, Lea and Blanchard, Philadelphia, London.

[22] Apfelberg, D.B., Maser, M.R. and Lash, H. (1976) The Use of Epidermis over a Keloid as an Autograph after Resection of the Keloid. The Journal of Dermatologic Surgery and Oncology, 2, 409-411. http://dx.doi.org/10.1111/j.1524-4725.1976.tb00211.x

[23] Weimar, V.M. and Ceilley, R.I. (1979) Surgical Gems: Treatment of Keloids on Earlobes. The Journal of Dermatologic Surgery and Oncology, 5, 522-523. http://dx.doi.org/10.1111/j.1524-4725.1979.tb00708.x

[24] Peacock, E.E. (1984) Wound Repair. W. B. Saunders, Philadelphia.

[25] Malaker, K. (2014) Keloid Prevention after Ear-Lobe Surgery. Middle East Scar Meeting Abst-SC4 March 2014, Dubai World Trade Center UAE, 44.

[26] Seegenschmiedt, M.H. and Strittmatter, H.J. (2008) Radiotherapy for Keloids and Hypertrophic Scars. MMW Fortschritte der Medizin, 150, 29-31.

[27] Brady, W.L. (2008) Radiotherapy for Non-Malignant Disorders. Springer Heidelberg, Berlin.

[28] Simmons, D.A. (1996) Patients with Keloids. Psychosocial Issues. Loss, Grief \& Care, 7, 121-132. http://dx.doi.org/10.1300/J132v07n03_11

[29] Bari, S., Choudhury, M.D. and Mahmud, I. (2001) Acid Burns in Bangladesh: Annals of Burn and Fire Disaster. XIV (3).

[30] Lawrence, W.T. (1991) In Search of the Optimal Treatment of Keloids: Report of a Series and a Review of the Li- terature. Annals of Plastic Surgery, 27, 164-178. http://dx.doi.org/10.1097/00000637-199108000-00012

[31] Malaker, K., Vijayraghavan, K., Hodson, I. and Yafi, T. (2004) Retrospective Analysis of Treatment of Unresectable Keloids with Primary Radiation over 25 Years. Clinical Oncology, 16, 290-298. http://dx.doi.org/10.1016/j.clon.2004.03.005

[32] Jeffry, M., Tyrone, J., Bonomo, S., Xia, Y. and Mustoe, T.A. (2000) Cellular Mechanisms for Diminished Scarring with Aging. Plastic and Reconstructive Surgery, 105, 1591-1599.

[33] Cohen, I.K., Diegelhann, R.F. and Kieser, H.R. (1976) Collagen Metabolism in Keloids and Hypertrophic Scars. In: Langacre, J.I., Ed., Ultrastructure of Collagen, Charles Thomas, Springfield, 199-212.

[34] Hall, E. and Giaccia, A.J. (2012) Linear Energy Transfer and Relative Biologic Effectiveness. In: Hall, E. and Giaccia, A., Eds., Radiobiology for the Radiologist, 7th Edition, Lippincott Williams \& Wolters Kluwer, Philadelphia, 105-113.

[35] Hall, E. and Giaccia, A. (2012) Chapter 27 Chemotherapy Agents from the Perspective of the Radiation Biologist. In: Hall, E. and Giaccia, A., Eds., Radiobiology for the Radiologist, 7th Edition, Lippincott Williams \& Wolters Kluwer, Philadelphia, 448-489.

[36] Williamson, J.F. and Brenner, D.J. (2008) Physics and Biology of Brachytherapy. In: Halprin, E.C., Perez, C.A. and Brady, L.W., Eds., Principles and Practice of Radiation Oncology, 5th Edition, Lippincott Williams and Wilkins, Philadelphia, 423-475.

[37] Overgaard, J. and Horsman, M.R. (1996) Modification of Hypoxia-Induced Radioresistance in Tumours by the Use of Oxygen and Sensitizers. Seminars in Radiation Oncology, 6, 10-21. http://dx.doi.org/10.1016/S1053-4296(96)80032-4

[38] Hall, E. and Giaccia, A.J. (2012) Radioprotectors. In: Radiobiology for Radiologists, Lippincott Williams \& Wilkin, Philadelphia, 129-134.

[39] Hall, E. and Giaccia, A.J. (2012) Chapter 23; Time Dose and Fractionation in Radiotherapy. In: Hall, E. and Giaccia, A., Eds., Radiobiology for the Radiologist, 7th Edition, Lippincott Williams \& Wolters Kluwer, Philadelphia, 391-411.

[40] Fowler, J.F. (1989) The Linear-Quadratic Formula and Progress in Fractionated Radiotherapy. The British Journal of Radiology, 62, 679-694. http://dx.doi.org/10.1259/0007-1285-62-740-679

[41] Yoshii, Y. (2008) Pathological Review of Late Cerebral Radionecrosis. Brain Tumour Pathology, 25, 51-58. http://dx.doi.org/10.1007/s10014-008-0233-9

[42] Hall, E.J. and Giaccia, A.J. (2012) Linear Energy Transfer and Relative Biological Effectiveness. In: Radiobiology for the Radiologist, Lippincott Williams \& Wolters Kluwer, Philadelphia, 104-113.

[43] Schneider, B.F., Eberhard, D.A. and Steiner, L.E. (1997) Histopathology of Arterio-Venous Malformations after Gamma Knife Radiosurgery. Journal of Neurosurgery, 87, 352-357. http://dx.doi.org/10.3171/jns.1997.87.3.0352

[44] Hall, E.J. and Brenner, D.J. (1993) The Radiobiology of Radiosurgery: Rationale for Different Regimes for AVMs and Malignancies. International Journal of Radiation Oncology \& Biology \& Physics, 25, 381-385.

http://dx.doi.org/10.1016/0360-3016(93)90367-5 
[45] Szeifert, G.T., Atterberry, D.S., Kondziolka, D., Levivier, M. and Lunsford, L.D. (2006) Cerebral Metastases Pathology after Radiosurgery-A Multicenter Study. Cancer, 106, 2672-2681. http://dx.doi.org/10.1002/cncr.21946

[46] Monboisse, J.C., Gardès-Albert, M., Randoux, A., Borel, J.P. and Ferradini, C. (1988) Collagen Degradation by Super Oxide Anion in Pulse and Gamma Radiolysis. Biochimica et Biophysica Acta (BBA), General Subjects, 965, 29-35. http://dx.doi.org/10.1016/0304-4165(88)90147-X

[47] Filali-Mouhim A., Audette, M., St. Louis, M., Thauvette, L., Denoroy, L., Penin, F., et al. (1997) Lysozyme Fragmentation Induced by Gamma-Radiolysis. International Journal of Radiation Biology, 72, 63-70. http://dx.doi.org/10.1080/095530097143545

[48] Assemand, E., Lacroix, M., Mateescu, M.A. and Alexandru, M.L. (200) L-Tyrosine Prevents Aggregation of Therapeutic Proteins by $\gamma$-Irradiation. Biotechnology and Applied Biochemistry, 38, 151-156. http://dx.doi.org/10.1042/BA20030038

[49] Schuessler, H. and Herget, A. (1980) Oxygen Effect in the Radiolysis of Proteins I. Lactate Dehydrogenase. International Journal of Radiation Biology, 37, 71-80. http://dx.doi.org/10.1080/09553008014550071

[50] Schuessler, H. and Schilling, K. (1984) Oxygen Effect in Radiolysis of Proteins Part II, Bovine Serum Albumin. International Journal of Radiation Biology \& Related Studies in Physics, Chemistry \& Medicine, 45, 267-268.

[51] Sloan, D.F., Brown, D. and Wells, C.H. (1978) Tissue Gases in Human Hypertrophic Burn Scars. Plastic \& Reconstructive Surgery, 61, 431-435.

[52] Kischer, C.W., Thies, A.C. and Chapil, M. (1982) Perivascular Myofibroblasts and Microvascular Occlusion in Hypertrophic Scars and Keloids. Human Pathology, 13, 819-824. http://dx.doi.org/10.1016/S0046-8177(82)80078-6

[53] Sahl, W.J. and Clever, H. (1994) Cutaneous Scars Part II. International Journal of Dermatology, 33, 763-769. http://dx.doi.org/10.1111/j.1365-4362.1994.tb00984.X

[54] Lee, Y.Y., Yang, C.C., Chao, S.C. and Wong, T.W. (2004) Histopathological Differential Diagnosis of Keloid and Hypertrophic Scars. American Journal of Dermatopathology, 26, 379-384. http://dx.doi.org/10.1097/00000372-200410000-00006

[55] Kischer, C.W. (1992) The Microvessels in Hypertrophic Scars, Keloids and Related Lesions: A Review. Journal of Submicroscopic Cytology and Pathology, 24, 281-296.

[56] Leventhal, D., Furr, M. and Reiter, D. (2006) Treatment of Keloids and Hypertrophic Scars: A Meta-Analysis and Review of the Literature. Archives of Facial Plastic Surgery, 8, 362-368. http://dx.doi.org/10.1001/archfaci.8.6.362

[57] Order, S.E. and Donaldson, S.S. (1982) Radiation Therapy of Benign Diseases. A Clinical Guide. 2nd Edition, Springer, Berlin, 182.

[58] Zuber, T.J. and DeWitt, D.E. (1994) Earlobe Keloids. American Family Physician, 49, 1835-1841.

[59] Music, E. and Engel, G. (2010) Earlobe Keloids: A Novel and Elegant Surgical Approach. Dermatologic Surgery, 36, 395-400. http://dx.doi.org/10.1111/j.1524-4725.2009.01452.X

[60] Zhang, Y., Cen, Y., Liu, X., Yu, R. and Xu, X.W. (2009) Clinical Improvement in the Therapy of Aural Keloids. Chinese Medical Journal, 122, 2865-2868.

[61] Flickinger, J.C. (2014) A Radiobiological Analysis of Multicenter Data for Postoperative Keloid Radiotherapy. International Journal of Radiation Oncology \& Biology \& Physics, 79, 1164-1170. http://dx.doi.org/10.1016/j.ijrobp.2009.12.019 
Scientific Research Publishing (SCIRP) is one of the largest Open Access journal publishers. It is currently publishing more than 200 open access, online, peer-reviewed journals covering a wide range of academic disciplines. SCIRP serves the worldwide academic communities and contributes to the progress and application of science with its publication.

Other selected journals from SCIRP are listed as below. Submit your manuscript to us via either submit@scirp.org or Online Submission Portal.
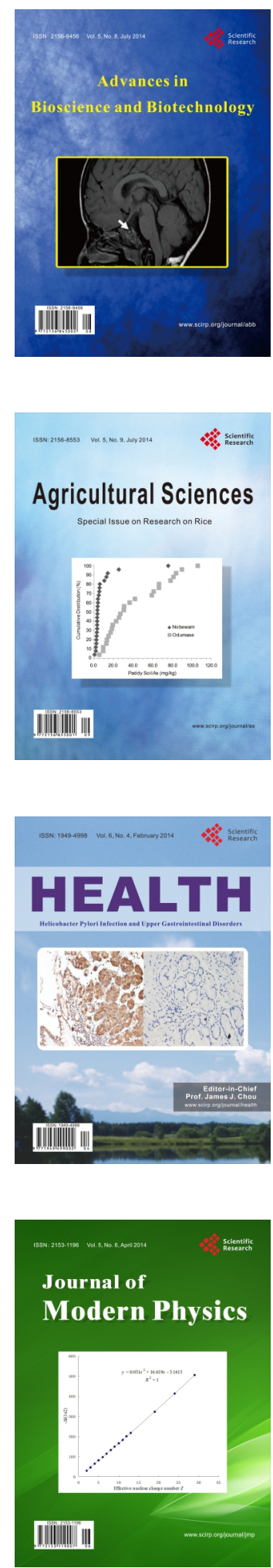
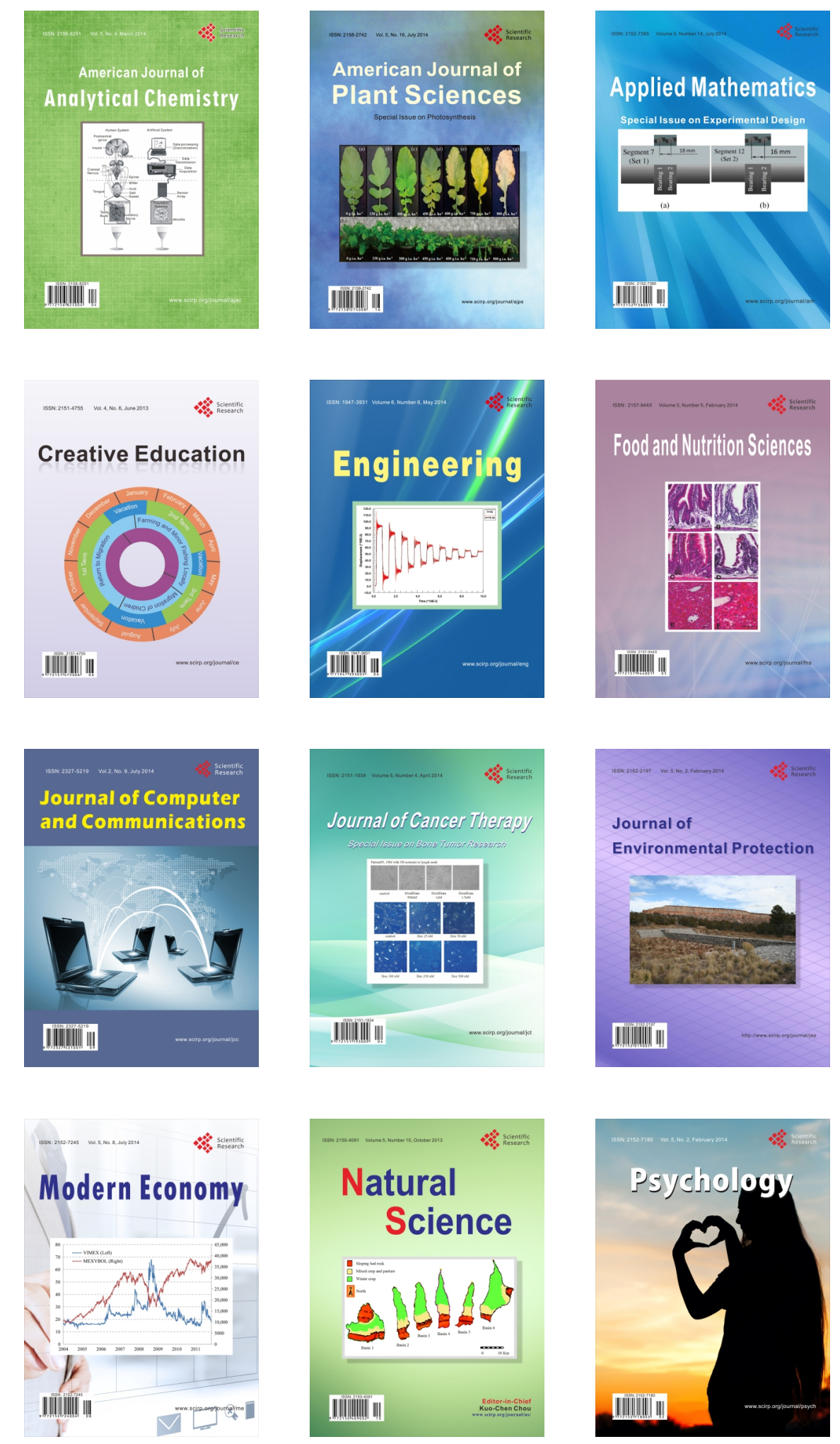